\title{
On Metonymy and Its Translation
}

\author{
Haicui Zheng ${ }^{1, *}$ \\ ${ }^{1}$ College of Foreign Languages, Inner Mongolia University, Huhhot, China \\ *Correspondence: College of Foreign Languages, Inner Mongolia University, Huhhot, 010070, China. E-mail: \\ zhenghaicui@yahoo.com
}

Received: November 25, 2014

Accepted: December 1, 2014 Online Published: December 10, 2014

doi:10.5430/wjel.v4n4p28

URL: http://dx.doi.org/10.5430/wjel.v4n4p28

\begin{abstract}
The past decades has witnessed a revolutionary change of metaphor and metonymy from being figures of speech to conceptual systems. Metaphor's status as a conceptual system has been widely recognized. However, metonymy has received relatively less attention than metaphor, but its status as a cognitive instrument is no less important than metaphor at all. Metonymy is grounded in people's experience, shaping people's cognition and facilitating language expression. This paper is an attempt to explore the properties of metonymy from the perspective of rhetoric, pragmatics and cognitive linguistics and then to discuss translations of English metonymies. Translations can manifest metonymy's evolution and cultural difference. The ultimate purpose is to throw light on the metonymies which sometimes puzzle the English language learners so as to facilitate English language learning.
\end{abstract}

Keywords: metonymy; a rhetorical device; a pragmatic act; a conceptual system; translation

\section{Introduction}

In the past decades, with the publication of Metaphors We Live By written by George Lakoff and Mark Johnson (1980), metaphor has undergone a revolutionary change in its status from a figure of speech to a conceptual system. Likewise metonymy has experienced the change and is believed to be a cognitive instrument as well. However, metaphor's status as a conceptual system has been widely recognized whereas metonymy has received less attention than metaphor. The following sections will explore features of metonymy and then discuss how to translate English metonymies into Chinese.

\section{Properties of Metonymy}

Metonymy catches people's attention mainly by its grammatical and logic oddness or semantic abnormity and is treated as a rhetorical device. Like other figures of speech, metonymy is a special language use and it can achieve certain communication effects. Besides being a rhetorical device, metonymy is also a means of referring to something and more important of all it is a thinking mode of people.

\subsection{Metonymy as a Figure of Speech}

Metonymy, etymologically speaking, comes from the Greek word "metonumia" which means "a change of name" (Li, 1998). Instead of referring to something directly, we can use some other terms related with it to refer to the specific thing. For example, we can use "skirt" to refer to a woman. There are a variety of metonymies such as using the instrument to refer to the agent and using the capital to refer to the country. There is a special kind of metonymy a part standing for the whole or the whole for a part, or the abstract for the concrete and vice versa, or material for object and vice versa. Such kind of figure of speech is called synecdoche in rhetoric. Though it is discussed by some scholars as a category of rhetoric $(\mathrm{Li}, 1998 ; \mathrm{Xu}, 2001)$, there is a tendency to admit that the distinction between synecdoche and metonymy is blurred and synecdoche is regarded as a special case of metonymy (Xu, 2001; Murphy, 2014), which involves part and whole relationship. In most cases, synecdoche is put under the category of metonymy. Out of the realm of rhetoric, it is not necessary to make a distinction between them. This paper follows this practice and does not make a distinction between metonymy and synecdoche, for they are both conceptual instruments involving reference based on the association or relatedness. The only difference between metonymy and synecdoche 
lies in the relationship between the referent and the referred. Their functions and working mechanisms in either reference or cognition are almost the same.

As rhetorical devices, metonymy can make the language expression convenient, concise and vivid. For example, the following sentences are common and frequent.

1) Shakespeare takes up the whole bottom shelf.

2) Can I borrow your Shakespeare?

3) Where is the cheese sandwich sitting?

In sentences 1) and 2), a figure of speech-metonymy can be identified. The proper name "Shakespeare" actually stands for the books written by him. So it is the metonymy AUTHOR FOR WORKS. In sentence 3), "the cheese sandwich" must refer to the customer who orders it and it is the metonymy using ordered food to refer to its customer. Take the metonymies away and make the sentences semantically correct and logically acceptable, and we will get the following sentences.

*1) The books written by Shakespeare take up the whole bottom shelf.

*2) Can I borrow your book written by Shakespeare?

*3) Where is the person who ordered cheese sandwich sitting?

The comparison clearly demonstrates the rhetorical effect of metonymy-concise and vivid. Though the above sentences (with the sign *) are normal and acceptable, they are not used in some situations. Instead, their simplified versions - sentences 1),2) and 3) are preferred due to their economical use of words.

\subsection{Metonymy as a Reference}

Metonymy helps people achieve the communicative purpose of expressing vividly and at the same time it performs the function of referring to something economically and effectively, thus getting the name "referential metonymy" (Warren, 1999).

Reference in pragmatics is "an act in which a speaker, or writer, uses linguistic forms to enable a listener, or reader, to identify something" (Yule, 2000, p.17). Reference involves referring to something on the part of the speaker or the writer and making an inference on the part of the hearer or the reader. It requires a collaborative work from both parties of the conversation. A successful reference occurs when the speaker or writer makes a good choice of referring expression and have a reasonable expectation of the hearer or reader's ability to make the correct inference. In other words, the speaker's linguistic choice is based on his/her belief that the hearer can figure out what he/ she refers to with cognitive efforts - making inferences.

In reference, there is a conventional assumption that certain referring expressions are used to designate certain entities. For example, Shakespeare, the proper name, is assumed to be used to identify the great person and "the cheese sandwich" to identify a food. However, such assumption is proved to be limited and partial. More examples will shed light on it.

4) Brazil wins World Cup.

5) Moscow and Washington will hold talks on this problem.

Such kinds of examples are common and frequent in English language. Brazil, Moscow and Washington are all names of countries or cities. How can a country win a football match? How can two cities hold talks? Metonymies are involved. The country name and city names are used metonymically, referring to the soccer team of Brazil in sentence 4) and to the governments (CAPITAL FOR GOVERNMENT METONYMY) in sentence 5).

So the referring expressions can be used to designate anything related with them. In other words, an expression provides "a range of reference", (Yule, 2000, p.21) and may be used to identify any entity in a number of possible referents. There exists a pragmatic connection, not just a direct one-to-one relationship between names and objects. The regular referring or designating function of an expression may be invested with some features in some situations. Therefore the interpretation of the reference may require a local socio-cultural context.

In sum, metonymy actually performs the function of reference. There is no direct relationship between a linguistic expression and the entity in the world. There may exist a pragmatic connection. Since reference is "a social act" context dependent and culturally influenced, metonymy is invested with social and cultural features. Translations of metonymies will reveal the cultural influence. 


\subsection{Metonymy as a Cognitive Instrument}

Besides being a rhetorical device and a means of achieving reference, metonymy also serves the function of providing understanding (Lakoff \& Johnson, 1980, p. 36). The cognitive feature of metonymy is so fundamental that it has not come into people's view for such a long time. It is Lakoff and Johnson who first revealed the cognitive property of metaphor and metonymy in 1980s. And many scholars have conducted more studies about the cognitive nature of metaphor and metonymy (Casasanto, 2009; Gibbs, 1999). Instead of being a poetic imagination and language ornament out of choice, metaphor and metonymy are modes of thinking pervasive not only in language use but in people's daily life. "Like metaphors, metonymic concepts structure not just our language but our thoughts, attitudes, and actions" (ibid: 39). Main claims made by cognitive linguists about metaphor also apply to metonymy (Lakoff \& Turner, 1989, p.103, cited in Ungerer \& Schmid, 1996, p. 128; Zhao, 2000; Liu, 2011).

Despite their similar role of helping people understand one thing by means of another, metonymy is different from metaphor in its working mechanism. Many scholars (see Lakoff \& Johnson, 1980; Lakoff, 1993; Indurkhya, 1992; Gluksberg, 1993; Turner, 1996; Su, 2000; Haser, 2005) have studies how metaphor and metonymy work in people's mind. Metaphor involves two domains and mapping occurs between the two domains due to the similarity between the two cognitive models. In the case of metonymy, only one domain is involved. Metonymy requires contiguity or association. Mapping between the two entities in one domain is based on their relatedness. Similarity triggers metaphor while connection and salience trigger metonymy. For example, any part of human body can be used metonymically to refer to people.

6) There are a lot of good heads in the university.

7) We've got some new blood in the organization.

8) More hands make light work.

In a university, intelligence is valued and "good heads" stand for intelligent people. Sentence 7) contains both a metonymy - BODY PART FOR PERSON and a metaphor-ORGANIZATION IS PERSON. Since the organization is thought of as a person, new people are just like new blood, making the organization stronger and more energetic. As to sentence 8), while doing things, people use their hands, which is the salient part in the work ICM (Idealized Cognitive Model) (Lakoff, 1987). In the different ICMs involved in the above three sentences, the referred entity is common - person, which take the form of different metonymies, for different things come into the foreground. So metonymies come out on the basis of the salient part of each ICM.

Radden and Kovecses (1999) argue that in ICM of metonymy, the vehicle, the source entity, provides an easy mental access to the target entity and language is metonymical in nature. They argue that since people tend to use language economically to express their thoughts, the conceptual system - metonymy makes it possible for people to express themselves concisely. Therefore, people's thinking is metonymical and it turns out that we live by metonymies (Liu, 2011, p.147). Metonymic concepts are grounded in people's experience and language. Their grounding is supposed to be more obvious than that of metaphoric concepts, for metonymy usually involves direct physical or casual associations (Lakoff \& Johnson, 1980, p.39). Metonymy is so basic and fundamental to people's thinking that its cognitive nature usually slips people's mind and attention easily.

As the comparison between sentences 1), 2), 3) and sentences * 1), *2), *3) in Section 2.1 shows, metonymy makes language expression concise and vivid. This is in conformity with people's cognitive tendency. People always tend to exert the smallest effort to achieve the expected effect based on the relevance. An ostensive or successful communication is presumed to have achieved optimal relevance (Sperber \& Wilson, 1986). In the case of metonymy, the referred entity can be figured out as long as it is relevant enough to the referent. Take sentences 4) and 5) again as example.

4) Brazil wins World Cup.

5) Moscow and Washington will hold talks on this problem.

In sentence 4), World Cup as a football match between teams from different countries is shared knowledge. When it comes to the final result of the match, which country wins is the attention focus. Therefore Brazil, the country name becomes the salient in this script. The country name is relevant enough to achieve the communication purpose and the word "team" is not necessary to appear. COUNTRY FOR TEAM metonymy based on the optimal relevance makes the statement clear to the readers.

The same applies to sentence 5) though different metonymies-CAPTICAL FOR GOVERNMENT are involved. The words "hold talks" create a schema in which the salient element is the participants - the countries or regions 
representing different interests. Therefore the capital where the government locates comes to the foreground. Here readers' attention is focused on the Russian government and the American government rather than the two cities Moscow and Washington.

To sum up, metonymy is not an intended language choice as a language ornament. It is a basic mode of thinking, using one entity to refer to another relevant entity. Mapping from the source domain to the target domain occurs because of the contiguity or association.

\section{Metonymy and Translation}

Since metonymy is grounded in people's experience and thinking, metonymies of various kinds are pervasive in language expression. The conceptual nature of metonymy enriches the vocabulary of English language. Due to the similar thinking pattern, some metonymical expressions can be found in both English and Chinese. For example, "we need more hands" has an equivalent expression in Chinese 我们需要更多的人手. It is a word-for-word translation. For the language learners, a good command of the cognitive nature of metonymy is of great help in their vocabulary enlargement and language acquisition. On the contrary, if the learners have no idea of metonymy's function as conceptual system, they will find it hard to understand some sentences and cannot make the expected inference. In other words, a clear understanding of metonymy's nature facilitates language understanding and translation while little or partial knowledge of metonymy will be a hindrance to them. Translations of metonymies are a manifestation of learner' understanding of metonymy.

However, there are some other metonymical expressions which show the influence of some particular culture and will create some difficulties for readers of other cultures. For example, the sentence "That individual is quite the silver fox" is difficult for the Chinese learners to figure out the metonymy and therefore it is hard for them to translate it. More elaborations will come in the following sections.

\subsection{Conventional Metonymy and Literal Translation}

Metonymy is a conceptual instrument, molding people's thinking and helping them express effectively. Some metonymies are so fundamental that they have developed into conventional language usage and become a dictionary entry. The only problem left is to decide which meaning is expected or suitable in the sentence. Under such circumstances, it is easier for those who can figure out the metonymy to identify and make a right decision among the list of different meanings. One can take the meaning required directly from the dictionary. So it is a kind of literal translation.

9) College students have to develop their capabilities of handling finances, choosing their own wardrobes, and determining their daily agenda.

\section{大学生必须培养打理财务、选择着装、确定日程安排的能力。}

In the dictionary, the meaning of wardrobe is "a piece of furniture in which one hangs up clothes" (the first entry, 衣 柜 in Chinese) and it can also refer to “the clothes that someone has" (the second entry, 衣服, 衣着, or 服装). The second meaning is metonymically developed from the first one, that is, CONTAINER FOR CONTENTS.

10) She tiptoed into the room

她踮着脚（蹑手蹑脚地）走进房间。

When tiptoe is used as a verb, its meaning is related with its noun form（脚趾 or 脚尖）. Here is MANNER FOR ACTION metonymy.

In the above two examples, the metonymies are manifest. The association or relatedness between the source entity and the target entity is close and a direct translation makes the meaning clear and acceptable in the target language. However, in some other cases, metonymies are not manifest either because of the loose association or the cultural difference.

11) He has been called to the bar. 他已取得律师资格。

The word "bar" has several meanings listed in the dictionary. One of them is "the division in a court of law" which is used metonymically to refer to the lawyers. Therefore "be called to the bar" has developed into a set phrase which means "to become a lawyer". It involves two metonymies-SOMETHING IN A PLACE FOR PLACE and PLACE FOR OCCUPATION. In the English culture, the bar is the salient part in the court, which is metonymically used to refer to the occupation and then to the legal practitioners. However, such association is not so salient in Chinese and the Chinese learners may have difficulties in translating the sentence. 
12) She has a sharp tongue.她一张嘴相当厉害, 说话尖刻。

In Chinese, the character 嘴 is mentioned instead of tongue (舌头). People's modes of thinking in English and Chinese are similar but the salient part in their conceptual system varies. In the talking ICM, tongue is the salient to the English people while mouth to the Chinese people.

13) She has an eye for beauty. 她有审美能力。

Similarly, the Chinese character 眼睛 for "eye" does not appear. The real meaning rather than the literal meaning is offered. In other words, the sentence is translated after it is paraphrased. Though it is not a literal translation of the word "eye", the meaning is a direct entry in the dictionary.

14) Life is a battle from the cradle to the grave. 人生从生到死都是一场战斗。

In this sentence, cradle (摇篮) and grave (坟墓) do not appear literally in the translation. But "from the cradle to the grave" is a set phrase which is translated into从生到死 in the dictionary.

Above are examples of metonymies that have been conventionalized and become an entry in the dictionary. Their translations have become a convention, too. To such kind of metonymies, learners can take the meaning directly from the dictionary. Sometimes, if they can identify the metonymies, they can produce the correct understanding and translation without consulting the dictionary. In other words, the metonymic thinking can help learners enlarge their vocabulary and facilitate language learning effectively.

\subsection{Free Metonymy and Liberal Translation}

Free metonymy refers to that kind of metonymies which have not become a dictionary entry. People have to figure out the intended meaning. In the translation, the metonymies have to be made apparent. Liberal translation here means learners have to translate flexibly since they cannot get the meaning directly from the dictionary. The translation strategies may involve adding words, changing words, or paraphrasing, etc.

15) Pearl Harbor still has an effect on their foreign policy.

$$
\text { 珍珠港(事件)仍然影响着他们的对外政策。 }
$$

The PLACE FOR EVENT metonymy has to be revealed in the translation. The word "event" (its Chinese equivalent is 事件) must appear. The Chinese characters in the brackets are added to make the metonymy explicit. Otherwise, the translation is incomplete and unacceptable. This is also true to the following examples.

16) The kettle is boiling.

$$
\text { 壸(里的水)开了。 }
$$

17) The hall applauded.

$$
\text { 大厅(里的人)鼓起掌来。 }
$$

The CONTAINER FOR CONTENTS metonymy in 16) and PLACE FOR PEOPLE metonymy in 17) have to be made clear in the translation. The added characters in the brackets are absolutely necessary in Chinese.

18) I would only accept offers of rides, food and a place to rest my head.

我只接受提供搭顺风车、食物和夜间落脚地的帮助。

Here is a PART FOR WHOLE metonymy. The expression “to rest one's head" (the literal translation is 休息我的头) actually means "to take a rest". In Chinese, there is a similar metonymical thinking, but "foot" (脚) instead of "head" (头) is involved. Therefore the translation “落脚地” is a strategy of domestication.

19) My father followed the plough all his life.

$$
\text { 我的父亲一辈子务农。 }
$$

Here is an INSTRUMENT FOR ACTION metonymy. The literal translation of plough犁is not acceptable. The sentence is translated after paraphrasing.

20) Are we boys going to be beaten by a bunch of skirts?

$$
\text { 难道我们男子汉会输给一伙女人? }
$$

Here is a DRESS FOR PEOPLE metonymy. Skirt is the typical dress of women (女人) and the metonymy is made manifest in the translation.

21) He liked the cup a bit too much. 


\section{他太贪杯了/他太能喝了。}

A CONTAINTER FOR CONTENTS metonymy is involved in the sentence. The implied or real meaning is "He like drinking too much". In Chinese there is an equivalent expression贪杯. It seems the literal translation of “cup" (杯) is kept, but it is a liberal translation, for the phrase 贪杯 means different. The literal translation of the whole sentence 他太喜欢这个杯子了 has a completely different meaning from the original sentence.

There are some metonymies which are novel or creative, which require people's cognitive efforts in understanding and translation.

22) The wolf and the pig mingled together in his face.

$$
\text { 他的脸上显出残暴和贪婪交织在一起的表情。 }
$$

23) The gentleman in me made me stand up to go away, but the journalist in me made me stand still.

$$
\text { 我的君子风度使我站起来告辞, 然而我的记者本能却使我站住不动。 }
$$

These two sentences involve Category-and-Property ICM. Literal translations of the two sentences make no sense at all. In 22) the wolf and the pig actually refer to the typical characteristics of the wolf and the pig or their connotations - cruelty and greed. These two meanings have to be made clear in the translations. The association of the two animals may vary in different cultures. "Pig" is associated more with being dirty or stupid in Chinese than with being greedy in English. And "face" here is a conventional metonymy, which takes the dictionary meaning "expression".

Sentence 23) contains a novel metonymy. The words "gentleman" and "journalist" here refer to the spirit, manner or ethos of gentleman and journalist. The interpretation of creative metonymies requires common sense, social knowledge and cultural awareness. They are the most difficult part in metonymy understanding and translation.

Like the metonymy concerning pig in sentence 22), cultural influence causes difficulty in metonymy translation.

24) That individual is quite the silver fox.

25) The letters have been bogged down in bureaucratic red tape.

The phrase "the silver fox" in sentence 24) refers to "a sexually attractive person" which is an informal usage in American English. In Chinese, "fox" has one connotation of being clever and deceitful and another connotation of being sexy and seductive. But still Chinese learners are not sure about what "the silver fox" metonymically refers to, for as far as culture is concerned, people have a common sense that the expression cannot be interpreted superficially.

Sentence 25) is difficult for the Chinese readers if they do not know the metonymical use of "red tape". They cannot identify the metonymy due to their ignorance of the old tradition in England that people used red tape to bind files and papers, which has been used metonymically to refer to the complicated bureaucratic procedures. There are similar expressions in English such as "blue stocking" (a metonymy referring to a well-educated woman) which take a strong cultural color.

\section{Conclusion}

Metonymy catches people's attention mainly by its grammatical and logic oddness or semantic abnormity and has been treated as a rhetorical device for a long time. Like other figures of speech, metonymy is a special language use and it can achieve certain communication effect. However, this is only the tip of the iceberg. With people probing into it, more about metonymy has been revealed. Metonymy helps people achieve the communicative purpose of referring to something economically and effectively. Metonymy is a conceptual system, shaping people's thinking and facilitating people's communication. Some metonymies are so fundamental that they have become an entry in the dictionary. People can just remember them and translate them literally. Some other metonymies require flexible or liberal translation. The metonymies have to be revealed or made manifest by means of adding words, changing words or paraphrasing.

By exploring the properties of metonymy, the less well known conceptual system, this paper aims to provide a comprehensive picture of it. Metonymy is valued with its rhetorical effect, cognitive nature and pragmatic function. Translation of metonymies is a criterion to check people's comprehension of metonymy. Since people of different cultures have a lot in common in cognition which is based on embodied mind, many metonymies in English can find their counterparts in Chinese, which makes it easy for learners to understand and translate the sentences containing such kind of metonymies. However, there are creative metonymies or culture-loaded metonymies which will create difficulties for learners of different cultures. Anyway a good command of metonymy can improve people's 
comprehension. Metonymy as a cognitive instrument facilitates language learning and enhances people's cultural awareness.

This research has been funded by the project "Multimodal Discursive Construction of Mongolian Identity-Interpreting Grassland Songs" supported by the Ministry of Education of the P.R. China (No.13YJAZH139).

\section{References}

Casasanto, D. (2009). When is a linguistic metaphor a conceptual metaphor? In Evans, V. \& S. Pourcel (Eds.) New Directions in Cognitive Linguistics. Amsterdam: John Benjamins Pub Co. http://dx.doi.org/10.1075/hcp.24.11cas

Gibbs, R. (1999). Researching metaphor. In Cameron, L. \& G. Low (Eds.). Researching and Applying Metaphor. Cambridge: Cambridge University Press.

Gluksberg, S., \& B. Keysar. (1993). How metaphor works. In Ortany A. (Ed.) Metaphor and Thought. London: Oxford University Press. http://dx.doi.org/10.1017/CBO9781139173865.020

Haser, V. (2005). Metaphor, Metonymy, and Experientialist Philosophy: Challenging Cognitive Semantics. Berlin/ New York: Moulton de Gruyter. http://dx.doi.org/10.1515/9783110918243

Indurkhya, B. (1992). Metaphor and Cognition: An Interactional Approach. Dordrecht: Kluwer Academic Publishers. http://dx.doi.org/10.1007/978-94-017-2252-0

Lakoff, G. (1987). Cognitive models and prototype theory. In Ulric Neisser (Ed.). Concepts and Conceptual Development: Ecological and Intellectual Factors in Categorization. New York: Cambridge University Press, 63-100.

Lakoff, G. (1993). The contemporary theory of metaphor. In Ortany A. (Ed.) Metaphor and Thought. London: Oxford University Press. http://dx.doi.org/10.1017/CBO9781139173865.013

Lakoff, G., \& M Johnson. (1980). Metaphors We Live By. Chicago \& London: The University of Chicago Press.

Lakoff, G., \& M Turner. (1989). More Than Cool Reason: A Field Guide to Poetic Metaphor. Chicago \& London: The University of Chicago Press. http://dx.doi.org/10.7208/chicago/9780226470986.001.0001

Li, Shiping. (1998). A Study of English Rhetoric. Changsha: Hunan People's Press.

Liu, Yuhong. (2011). A Multi-perspective Study of Metaphor. Beijing: World Book Publication.

Murphy, P. (2014). Synecdoche and metonymy. Retrieved November, 2014 from http://www.worldwidewords.org/qa/qa-syn1.htm

Radden, G., \& Z. Kovecses. (1999). Towards a theory of metonymy. In Panther, Klaus-Uwe \& Radden, G. (Eds.) Metonymy in Language and Thought. Amsterdam \& Philadelphia: John Benjamins Publishing Company, 17-59.

Sperber, D., \& D. Wilson, (2001). Relevance: Communication and Cognition. Beijing: Foreign Language Teaching and Research Press.

Su, Dingfang. (2000). Studies in Metaphor. Shanghai: Shanghai Foreign Language Education Press.

Turner, M. (1996). Blending and metaphor. In Y. Shen \& A. Kasher. (Eds.) Cognitive Aspects of Metaphor. Amsterdam: John Benjamins Publishing Company.

Ungerer, F., \& H-J Schmid. (1996). An Introduction to Cognitive Linguistics. Edinburgh: Addison Wesley Longman Limited.

Warren, B. (1999). Aspects of referential metonymy. In Panther, Klaus-Uwe \& Radden, G. (Eds.) Metonymy in Language and Thought. Amsterdam/Philadelphia: John Benjamins Publishing Company, 121-135.

White, R.M. (1996). The Structure of Metaphor: the Way the Language of Metaphor Works. Oxford: Blackwell.

Xu, Peng. (2001). Shakespeare's Figures of Speech. Suzhou: Suzhou University Press.

Yule, G. (2000). Pragmatics. Shanghai: Shanghai Foreign Language Education Press.

Zhao, Yanfang. (2000). An Introduction to Cognitive Linguistics. Shanghai: Shanghai Foreign Language Education Press. 